\title{
Ocorrência e morfologia de piritas goethitizadas no município de Formiga - MG
}

\author{
Occurrence and morphology of goethitized pyrites in the city of Formiga \\ $-M G$
}

\begin{abstract}
Anísio Cláudio Rios Fonseca ${ }^{1}$, Karina Santos Rios Fonseca ${ }^{1}$, Alexandre Cláudio Rios Fonseca ${ }^{1}$, Jordana Luísa de Castro ${ }^{2}$, Samila Elias Pinto ${ }^{2}$.
\end{abstract}

${ }^{1}$ Centro Universitário de Formiga - Unifor - MG, Formiga, Minas Gerais, Brasil.

${ }^{2}$ Universidade Federal de Lavras - Ufla, Lavras, Minas Gerais, Brasil.

\section{Resumo}

Introdução: Os pseudomorfos de goethita pós-pirita ocorrem no domínio sedimentar do Grupo Bambuí, possuindo hábito cúbico, octaédrico, dodecaédrico, combinações destes e formando agregados globulares esferoides. As regiões de Morro das Balas e Loanda são de importância histórica. Os estudos de Martins mostram a presença de quilombos, que lutaram contra as tropas do império. No livro Os Sertões, Euclides da Cunha descreve os materiais que os sertanejos usavam em suas armas de antecarga. Há relatos sobre coletas de pedras de hematita para uso como munição. Objetivos: Aferir dados morfológicos, mineralógicos e dimensionais das mesmas. Metodologia: Foram coletadas 1352 amostras globulares em três localidades e aferidos seus diâmetros, hábitos, estrutura interna, traço e densidade, utilizando-se paquímetro, câmera, microscópio estereoscópio e balança analítica. Resultados: Densidade média de $3,55 \mathrm{~g} / \mathrm{cm}^{3}$, com perda de $42,04 \%$ para o sulfeto original $\left(5,01 \mathrm{~g} / \mathrm{cm}^{3}\right)$, hábito cúbico e octaédrico em cristais isolados e nos agregados globulares, núcleo poroso e amarelo- avermelhado, traço amareloavermelhado, diâmetro médio dos agregados globulares de 19,97 mm e desvio padrão 8,22 mm. Conclusão: São restritos ao Grupo Bambuí, apresentando diferentes graus de pseudomorfose, dimensões abaixo de $88,06 \mathrm{~mm}$ e hábitos subordinados às condições bioquímicas de cada ocorrência, com predomínio do cubo, secundariamente octaedros e formas combinadas destes, com cristalizações de gerações diferentes.

Palavras-chave: Pseudomorfose; Hábito; Bactéria; Matéria orgânica.

Autor correspondente:

Anísio Cláudio Rios Fonseca

Endereço: Rua Georges Khouri, 200, Centenário

CEP 39100-000. Formiga (MG), Brasil.

Recebido em: 21/03/2019

Telefone: (37) 3322-1912

Revisado em: 07/09/2019

Aceito em: 11/10/2019

E-mail: anisiogeouniformg.edu.br

Publicado em: 13/12/2019 


\section{Abstract}

Introduction: The pseudomorphs of goethite after pyrite occur in the sedimentary domain of the Bambui Group, having a cubic habit, octahedral, dodecahedral, combinations of these and forming globular spheroidal aggregates. The Morro das Balas and Loanda regions are of historical importance. Martins studies show the presence of quilombos, who fought against troops of the empire.

In the book Os Sertões, Euclides da Cunha describes the materials that the sertanejos used in their preloader weapons. They are reported to collect pebbles of hematite for use as ammunition. Objectives: To gauge morphological, mineralogical and dimensional data. Methodology: 1352 globular samples were collected in three localities and their diameters, habits, internal structure, trace and density were measured using a pachymeter, camera, stereoscope microscope and analytical balance. Results: Average density of $3.55 \mathrm{~g} / \mathrm{cm} 3$, with loss of 42.04\% for the original sulfide (5.01 g/ cm3), cubic and octahedral habit in isolated crystals and globular aggregates, porous nucleus and reddish yellow, reddish-yellow trait, mean diameter of the globular aggregates of $19.97 \mathrm{~mm}$ and standard deviation $8.22 \mathrm{~mm}$. Conclusion: They are restricted to the Bambui Group, presenting different degrees of pseudomorphosis, dimensions below $88.06 \mathrm{~mm}$ and habits subordinate to the biochemical conditions of each occurrence, with predominance of the cube, secondarily octahedral and combined forms of these, with crystallizations of different generations.

Keywords: Pseudomorphosis; Habit; Bacterium; Organic matter.

\section{Introdução}

O município de Formiga- MG está situado entre a Bacia sedimentar do Cráton São Francisco e o Complexo Cristalino Arqueano Indiviso ${ }^{1,2,3,4,5}$. No domínio sedimentar, predominam os litotipos do Grupo Bambuí, membro do Supergrupo São Francisco. As localidades de Loanda, Morro das Balas, Cunhas e Padre Doutor estão situadas em áreas afetadas por eventos de transgressões e regressões marinhas há mais de 700 milhões de $\operatorname{anos}^{1,2,3,4}$, onde cada evento separadamente depositou uma série de rochas clásticas e carbonáticas.

Nas localidades estudadas (mencionadas no parágrafo anterior) os pseudomorfos se encontram associados à Formação Serra de Santa Helena, constituída por argilitos, siltitos, arenitos, arenitos (arcósios) e brechas intraformacionais. Nesse domínio, a ocorrência de pseudomorfos de goethita/hematita segundo a pirita (piritas limonitizadas) possui hábito esferoidal, mamelonar, renimorfo, estalactítico e formas associadas, bem como cristais isolados ${ }^{4,5,6}$.
Os pseudomorfos são estruturas que variam de hábitos mais elementares da pirita até formas combinadas como estruturas globulares esféricas a elipsoidais de estrutura radiada e/ou concêntrica devido à deposição sequencial de sulfeto, a exemplo dos coloides diversos que formam massas cristalinas botrioidais de outros minerais ${ }^{5,7}$. A pirita é mineral abundante em diversos locais, ainda que cristais bem formados e isolados sejam menos frequentes. Ela ocorre em abundância nos mais diversos ambientes e paragêneses8. Sua ocorrência em filões metalíferos de diversas temperaturas é muito constante, principalmente nos de origem hidroterma ${ }^{15,6}$.

A formação de pirita sedimentar foi um processo importante para controlar o nível de oxigênio da atmosfera e a concentração de sulfato na água do mar, ao longo do tempo geológico. A quantidade de pirita formada foi limitada pelas taxas de fornecimento de matéria orgânica decomposta, sulfato dissolvido e minerais de ferro detríticos reativos, onde, em condições euxínicas 
marinhas, produz-se $\mathrm{H}_{2} \mathrm{~S}$ e o fator limitante na formação de pirita é a disponibilidade de minerais de ferro reativos ${ }^{9}$.

Os xistos negros devonianos depositados no craton norte-americano contêm abundantes cistos de tasmanita (matéria orgânica), que são tipicamente preservados como discos circulares achatados em planos de acamamento, e podem ser preservados como moldes de preenchimento de pirita. A formação da pirita se dá dentro de cistos de tasmanita não comprimidos, onde a redução do sulfato bacteriano nestes moldes ocasionou a deposição de pirita framboidal, com posterior cimentação diagenética de pirita entre framboidos, na zona

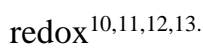

As associações de bactérias, algas, fungos, diatomáceas e cianobactérias formam biofilmes na interface sedimento-água em ambientes marinhos. A formação do biofilme, inicia-se com a adsorção de moléculas na interface água-sedimento e a limitação de nutrientes faz com que os organismos se tornem altamente interativos com íons metálicos presentes no ambiente ${ }^{13,14}$.

\section{Biomineralização ${ }^{11}$ é o processo de precipitação} de minerais por meio da ação de microrganismos (bactérias, algas, fungos) em que íons, em uma solução saturada, são precipitados. A presença de sulfetos de ferro, pirita e framboides funcionam como indicadores de ambientes redutores, anóxicos ou próximo da interface óxico/anóxico. A reação seguinte demonstra a formação da pirita13.

FeS amorfo $(\mathrm{Fe} 1,11 \mathrm{~S}-\mathrm{Fe} 1,09 \mathrm{~S}) \rightarrow$ makinavita $(\mathrm{FeS} 0,93-\mathrm{FeS} 0,96) \rightarrow$ greigita $\left(\mathrm{Fe}_{3} \mathrm{~S}_{4}\right) \rightarrow$ pirita $\left(\mathrm{FeS}_{2}\right)$.

A gênese dos agregados esféricos resultou de uma deposição pós ou sinconcrecional. Se pósconcrecional, a concreção foi formada primeiro e a pirita apareceu na fronteira com esse corpo. Se sinconcrecional, significa que ao mesmo tempo da formação, a pirita se formou em sua periferia. A substituição (pseudomorfismo) ocorre de molécula para molécula, lenta e progressivamente, mantendo a forma cristalina original. Daí, utiliza-se o termo original seguido de um adjetivo (mineral substituinte). O termo mais utilizado coloquialmente é "pirita limonitizada". Como a limonita designa uma mistura de óxi- hidróxidos de ferro utiliza-se o termo "pirita goethitizada" 15.

Vinculados a eventos de redução de matéria orgânica primitiva, estes sedimentos estão ligados a ambientes marinhos/lacustres.

Associados encontram-se pseudomorfos de piritas cúbicas/ octaédricas combinadas, hemisféricas, bem como formas mais complexas. A ocorrência destas dá-se em áreas muito vastas do cráton São Francisco. Este estudo está focado nas ocorrências das regiões de Loanda, Cunhas e Morro das Balas. Nesses locais, o aspecto desses minerais faz com que sejam imediatamente localizados na superfície do solo (stoneline aflorada). A forma desses agregados cristalinos lembra frutos do Cerrado como o araticum e, as protuberâncias são arestas de diversos cubos e octaedros agregados ${ }^{4}$. As regiões de Morro das Balas e Loanda possuem importância histórica, já que os estudos de Martins evidenciam a presença de quilombos nessas regiões que lutaram contra tropas do império ${ }^{17}$.

Na obra "Os Sertões"18, Euclides da Cunha descreve os materiais que o sertanejo utilizava em suas armas de antecarga para deter as tropas do governo que queriam debelar a rebelião organizada por Antonio Conselheiro. Cita que fabricavam pólvora utilizando salitre colhido à flor da terra e utilizavam a galena argentífera na obtenção do chumbo para fabricarem seus projéteis. Em relatos, é citado também que os sertanejos coletavam "pedrinhas de hematita" no solo para usar como munição.

A toponímia da localidade "Morro das Balas", no município de Formiga - MG, pode ser derivada dos combates de quilombos e tropas do império, está relacionada com o hábito dos pseudomorfos encontrados ali e que podem realmente ter sido utilizados como munição em armas de antecarga e bodoques ${ }^{17}$. A FIGURA 1 ilustra uma visão panorâmica do morro conhecido como Morro das Balas e seu Cruzeiro. 


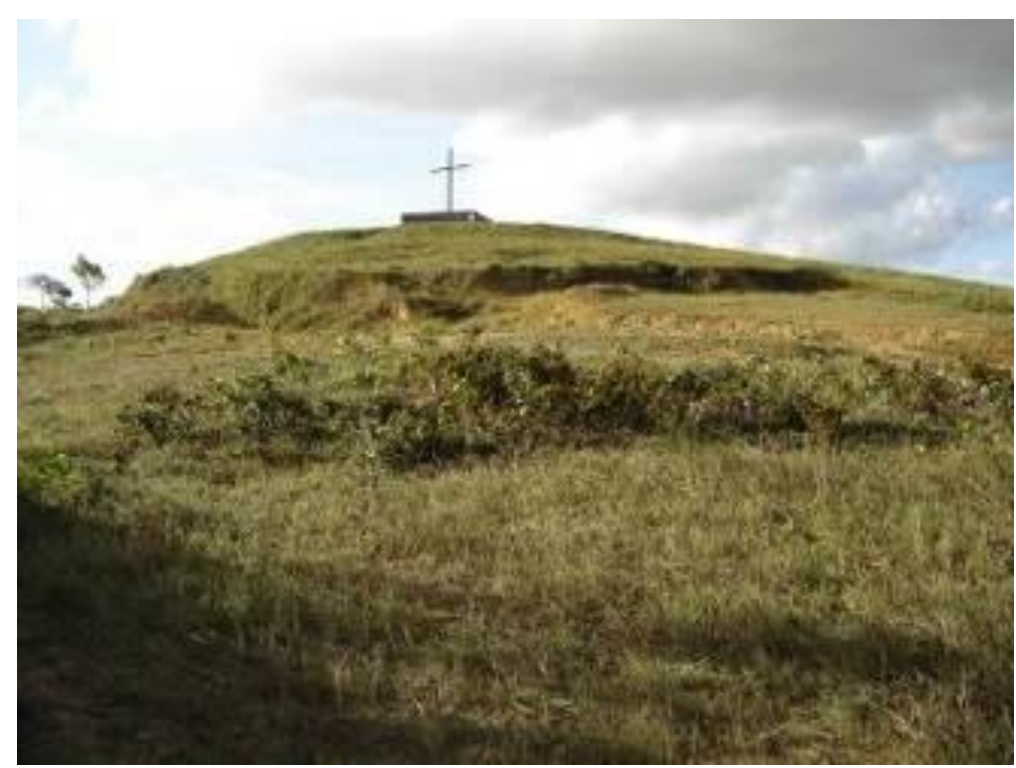

FIGURA 1: Região de Morro das Balas, tendo ao fundo o Cruzeiro, onde foram realizadas as primeiras coletas deste material.

Feições e hábitos esferoides são observados profusamente em Morro das Balas e Loanda. A FIGURA

2 mostra os mais frequentes.



FIGURA 2: Pseudomorfos de forma esférica (a maior com 3,6 cm). Morro das Balas e Loanda, Formiga- MG.

Na região da Loanda, há uma propriedade onde se encontram mais frequentemente agregados octaédricos com formas caprichosas, associados às rochas lateríticas ${ }^{6}$ da região. A variação térmica entre o dia e a noite provoca dilatações e contrações térmicas, terminando por dividir alguns agregados globulares nas proximidades de seu hemisfério $^{4,19}$.
As mineralizações octaédricas formam intercrescimentos, lembrando maclas de marcassita, com formas pontiagudas geométricas piramidais ${ }^{5,6}$. Há diversos intercrescimentos em forma concêntrica em núcleos elipsoidais capeados por gerações de drusas de piritas octaédricas, como as FIGURAS 3, 4 e 5. 



FIGURA 3: Octaedros de pirita goethitizada truncados (primeira imagem) e intercrescidos em núcleo elipsoidal (segunda imagem). Loanda, Formiga- MG.
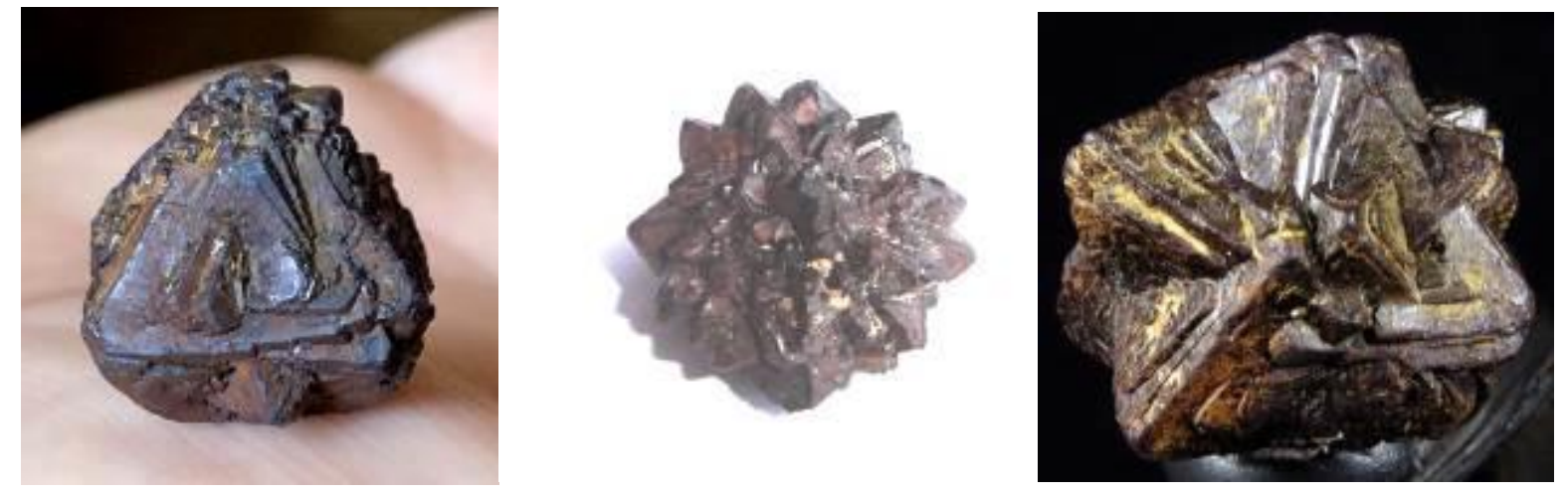

FIGURA 4: Arranjos complexos de octaedros de pirita goethitizada. A terceira imagem é de Rômulo Lubachesky. Loanda, Formiga- MG.

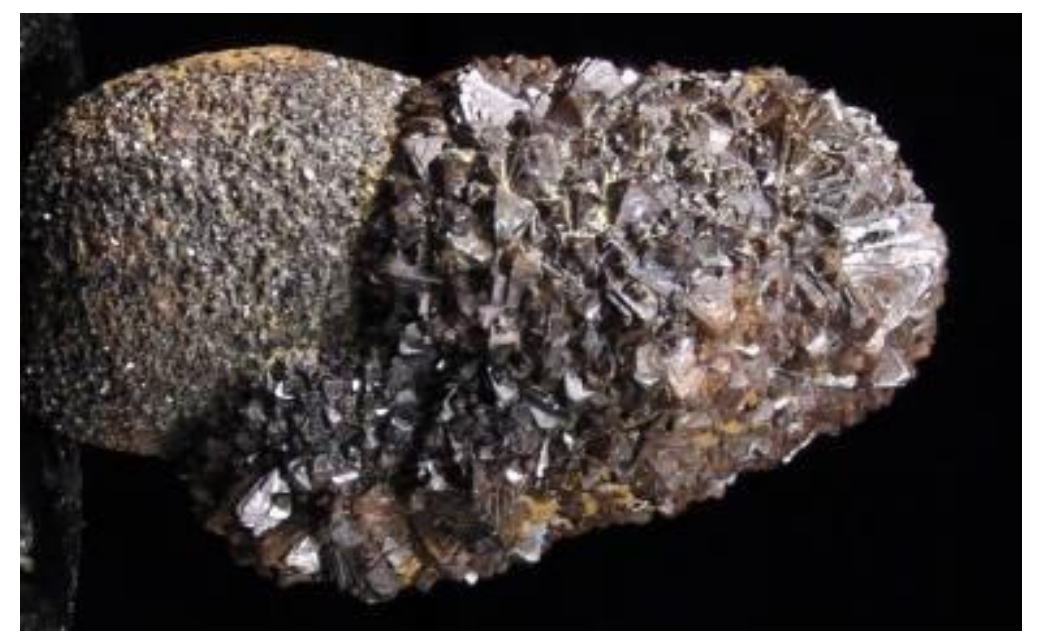

FIGURA 5: Drusa de pirita octaédrica limonitizada intercrescida sobre núcleo elipsoidal do mesmo mineral. Loanda, Formiga- MG. Foto de Rômulo Lubachesky. 
Ocorrência e morfologia de piritas goethitizadas no município de Formiga - MG

Formas elementares e combinadas de hábito octaédrico são encontradas em Loanda, Padre Doutor e Cunhas. Em Morro das Balas não foi observado nenhum espécime com hábito octaédrico ao longo de mais de trinta e cinco anos de coleta sistemática. As demais ocorrências ainda não são bem conhecidas nesse sentido. Os hábitos octaédricos de Cunhas e Padre Doutor são diferentes dos de Loanda, com cristais mais alongados segundo o eixo C (terceiro eixo cristalográfico). Sua íntima associação com outros hábitos da pirita é evidenciada, muitas vezes, em drusas que apresentam cristais cúbicos alternados com terminações pontiagudas de piritas octaédricas. É comum o truncamento dos cristais octaédricos no eixo $\mathrm{C}$.
Formas elementares ocorrem profusamente em todo o município, o cubo é o hábito mais frequente nas amostras. Em Morro das Balas, podem ser encontrados cubos, pentagonododecaedros e combinação do tipo cubo- octaedro.

O alto valor ornamental das amostras euédricas as torna ideais para confecção de bijuterias e intercâmbio com pesquisadores e museus, bem como para utilização em disciplinas de cristalografia e estudos sobre ambientes de formação destes sulfetos e posterior pseudomorfismo.

As FIGURAS 6, 7, 8 e 9 mostram cristais simples e combinados:

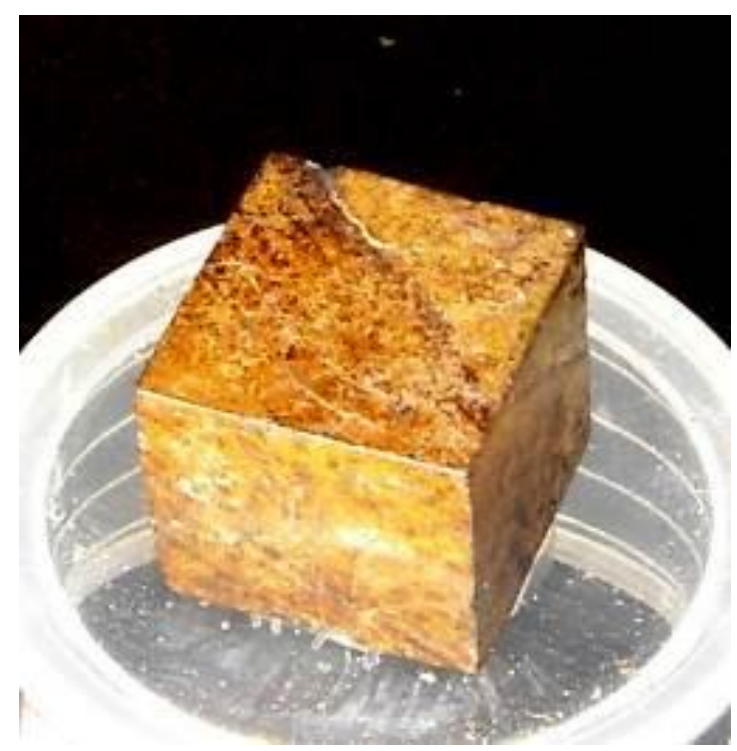

FIGURA 6: Cubo de $1 \mathrm{~cm}$ de aresta. Loanda, Formiga - MG.

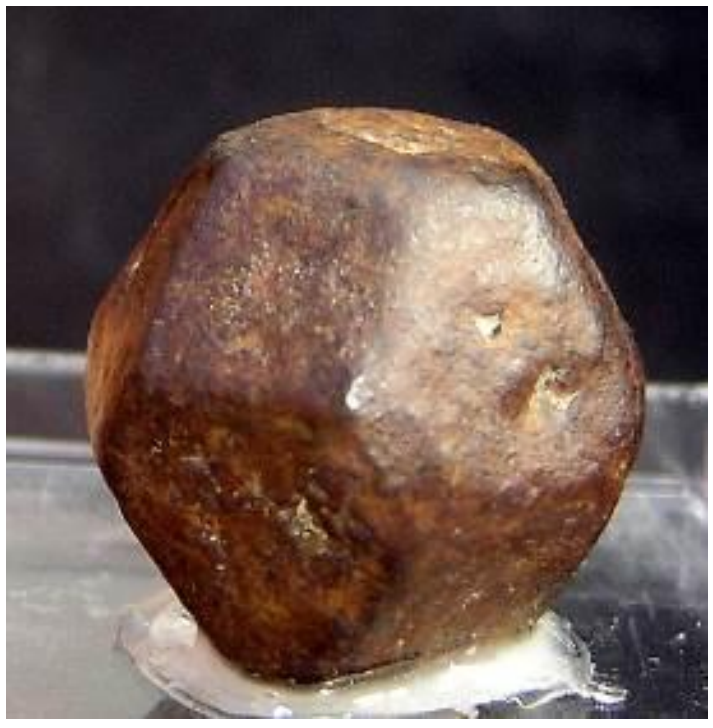

FIGURA 7: Forma combinada cubo octaedro. Morro das Balas, Formiga - MG. 


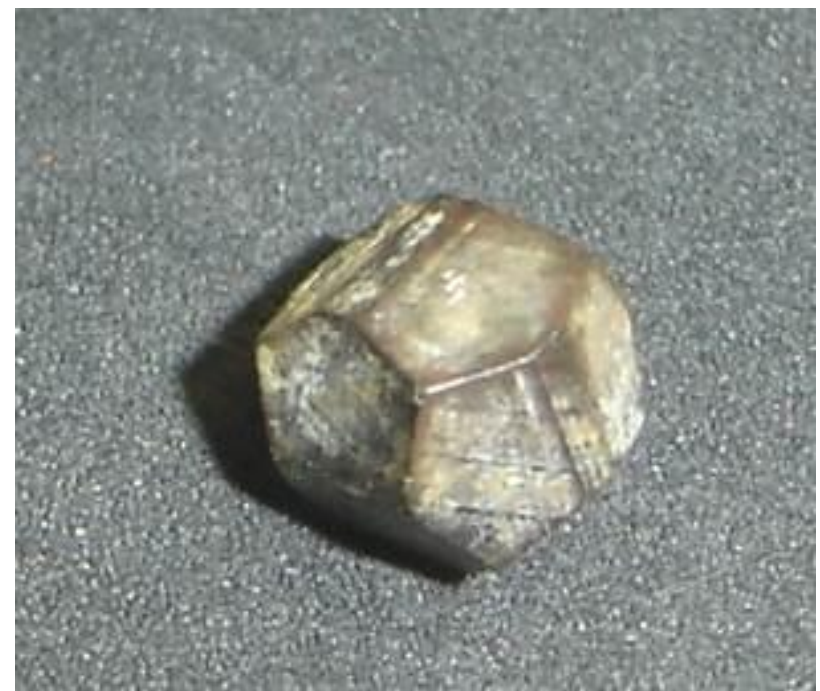

FIGURA 8: Pentagonododecaedro com $0,8 \mathrm{~cm}$. Formiga - MG.

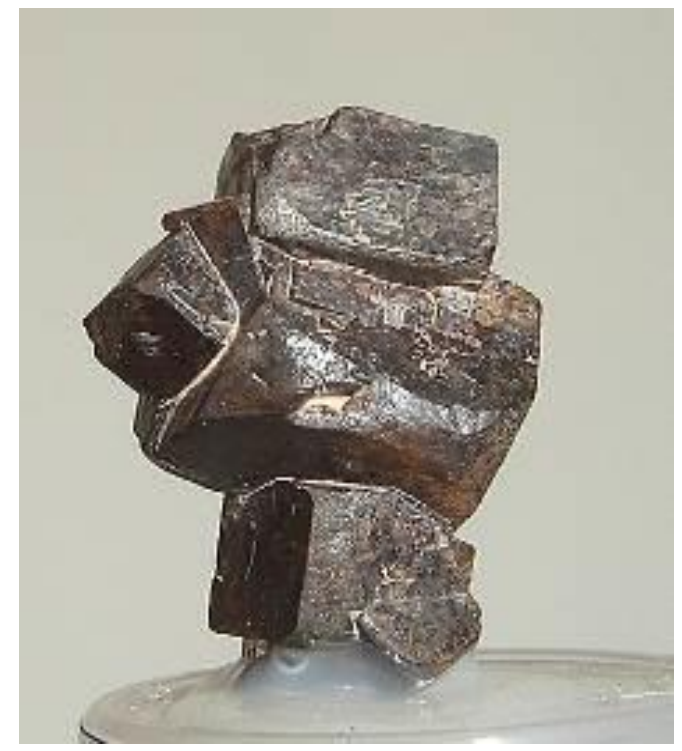

FIGURA 9: Intercrescimento de Cubos, Cunhas. Formiga - MG.

\section{Metodologia}

Para aferição de diâmetros e hábitos, foram selecionados apenas os agregados esféricos e elipsoidais por sua ampla distribuição, num total de 1352 unidades. As amostras foram coletadas em stonelines e na superfície do solo com auxílio de martelo estratigráfico Estwing. Foram acondicionadas em sacos plásticos tipo Ziplock e estojos plásticos com divisórias. Todas as amostras coletadas foram lavadas e utilizadas para obtenção de dados. Utilizou-se um paquímetro digital da marca Fowler para aferição dos diâmetros, câmera digital Samsung Cybershot 5.01 megapixels, microscópio estereoscópio
Tecnival de 80x para descrição da morfologia externa e interna dos agregados, balão de Erlenmeyer de $125 \mathrm{ml} \mathrm{e}$ balança analítica digital Gehaka BK 500 para cálculos de densidade. $\mathrm{O}$ ensaio de densidade foi realizado com lotes de glóbulos de até $20 \mathrm{~mm}$, perfazendo 169 amostras, limitadas pelo diâmetro do gargalo do balão de Erlenmeyer de $125 \mathrm{ml}$ utilizado. O balão de Erlenmeyer foi preenchido com água até a marca no gargalo e pesouse. Posteriormente, os lotes de pseudomorfos foram pesados. Depois, cada lote de amostras foi inserido no balão e completou-se com água até a marca preconizada, pesando-se logo em seguida. 
A densidade foi calculada a partir da fórmula:

$$
d=\frac{m 1}{m 2-(m 3-m 1)}
$$

Onde:

1. $\mathrm{m}_{1}=$ Massa das amostras dos tratamentos

2. $\mathrm{m}_{2}=$ Massa do balão de Erlenmeyer com água

3. $\mathrm{m}_{3}=$ Massa do balão de Erlenmeyer com água e amostras.

Foram realizadas 10 repetições com número de agregados variando de 15 a 20 em cada, restritos à capacidade volumétrica do balão e à capacidade da balança digital.

Testes de cor do traço em porcelana fosca foram realizados para se observar, também, quanto os espécimes se encontravam hidratados. Os exemplares foram analisados no microscópio estereoscópio para aferição de estrutura.

\section{Resultados e discussão}

A pirita cristaliza-se no sistema cúbico co, $^{5,6}$ e nos locais estudados há a ocorrência de cristais euhedrais.

O diâmetro dos agregados variou de 7,22 a 88,06 mm, com média $(\bar{X})$ de 19,97 mm e desvio padrão $(\mathrm{S})$ de $8,22 \mathrm{~mm}$. Apenas sete amostras apresentaram diâmetro superior a $50 \mathrm{~mm}$. As formas octaédricas identificáveis macroscopicamente perfizeram 16,66\% (224 espécimes). $\mathrm{Na}$ região de Loanda, predominam agregados globulares de cubos, mas a incidência de formas octaédricas é bem maior que o valor geral, perfazendo $26,32 \%$. A FIGURA 10 ilustra a dispersão.

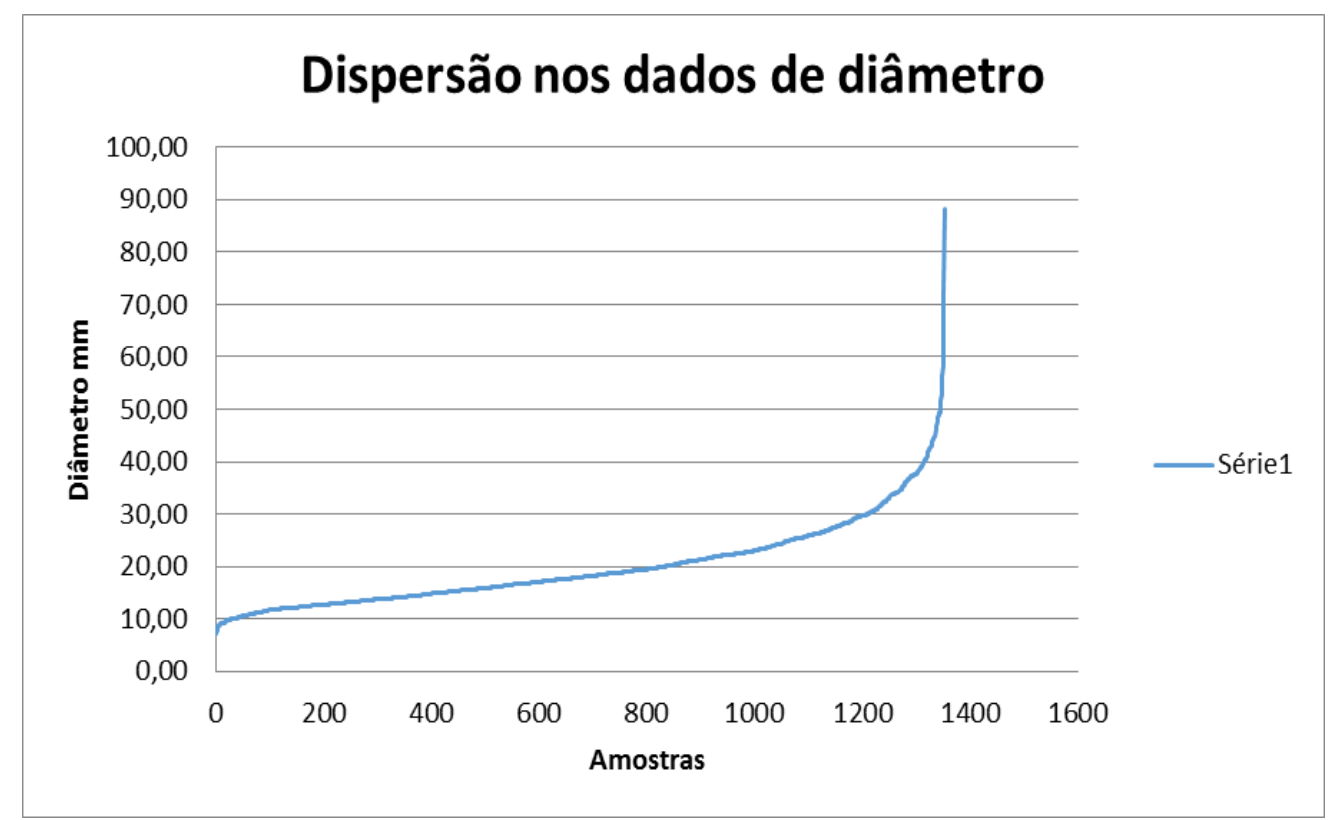

FIGURA 10: Dispersão nos dados de diâmetro dos pseudomorfos.

A maioria dos agregados está na faixa de 10-30 $\mathrm{mm}$ de diâmetro, havendo poucos exemplares com medidas extremas. Nas regiões de coleta, não foram encontrados glóbulos de grandes dimensões porque estas estão limitadas aos moldes que preencheram nos sedimentos no passado geológico. Os agregados de Morro das Balas são de cristais cúbicos, ocorrem formas isoladas de cubo-octaedro e pentagonododecaedro. Não foram encontradas formas octaédricas simples em Morro das Balas. Os agregados de Cunhas são predominantemente cúbicos, tendo sido coletados apenas dois agregados octaédricos nessa região, para este trabalho. Da localidade de Padre Doutor, foram obtidos para estudo apenas dois 
agregados, ambos octaédricos, mas a região ainda não foi estudada quanto a esse aspecto.

Muitos dos agregados globulares se encontram em diferentes estágios de hidratação e alteração devido às intempéries características de climas quentes e úmidos. Agentes físicos e químicos conjugados aceleram muito o intemperismo destes minerais. A perda em densidade dos agregados originais de pirita $\left(\operatorname{com~} \mathrm{d}=5,01 \mathrm{~g} / \mathrm{cm}^{3}\right)^{13}$ para $\mathrm{o}$ valor médio $(\bar{X})$ encontrado de $3,55 \mathrm{~g} / \mathrm{cm}^{3}$ foi de $29,15 \%$. Isso se deu devido à porosidade resultante do pseudomorfismo e formação de goethita, cuja densidade (em torno de $3,8 \mathrm{~g} / \mathrm{cm}^{3}$ ) é menor que a da pirita.

A média $(\bar{X})$ encontrada foi de $3,55 \mathrm{~g} / \mathrm{cm}^{3}$ e desvio padrão $(\mathrm{S})=0,053 \mathrm{~g} / \mathrm{cm}^{3}$. A FIGURA 11 ilustra a dispersão dos dados de densidade.

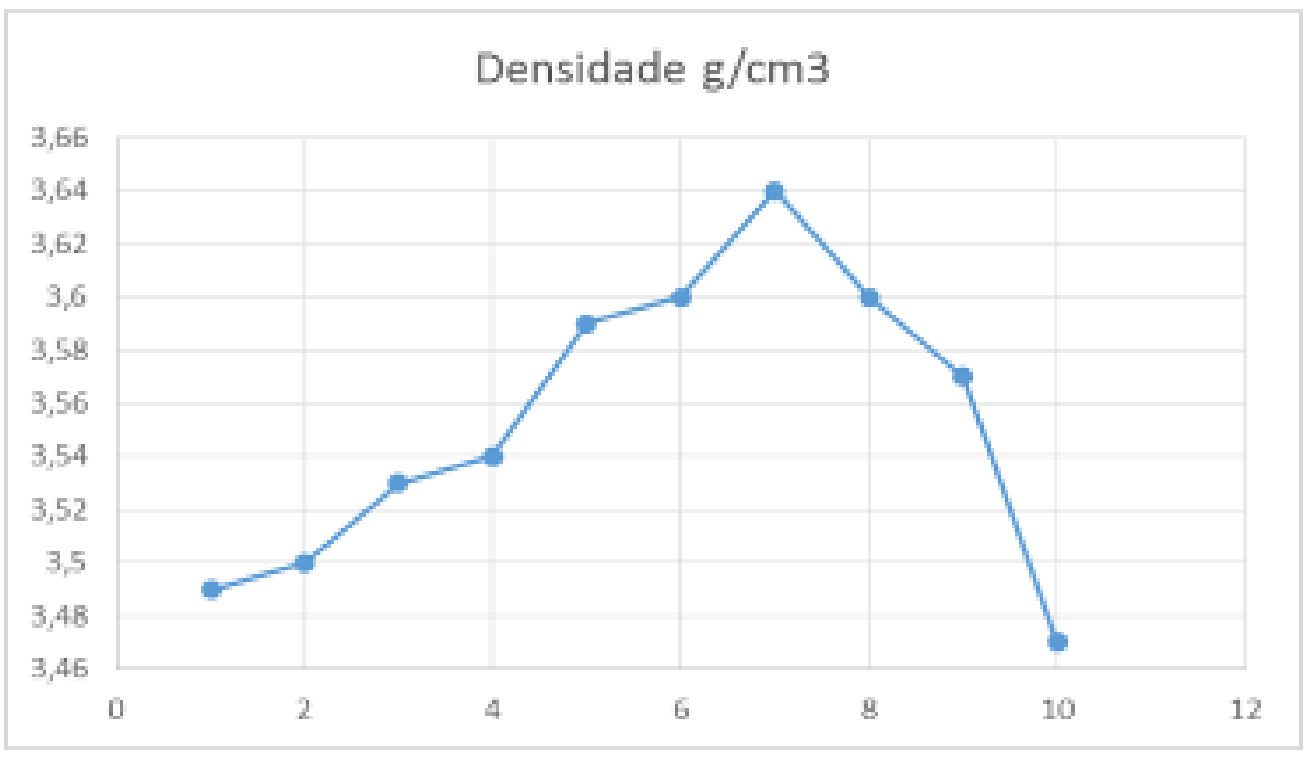

FIGURA 11- Dispersão dos dados de densidade nos tratamentos.

A variação na densidade é menor que $5 \%$ nos exemplares analisados, o que indica uma relação estável entre a composição da crosta e do núcleo dos agregados, bem como sua relação de porosidade.

Para análise morfológica interna, foram separados 60 exemplares sem terminações euédricas (para não destruir amostras colecionáveis) e sem critério de diâmetro. Foram partidos a martelo sobre uma seção de trilho e selecionados morfologicamente de acordo com a estrutura interna e cor do núcleo, os quais têm ligação direta com seu grau de hidratação. Notou-se uma diferenciação no processo de pseudomorfose devido à desidratação de sua superfície em contato direto com o meio externo formando, assim, uma estrutura nucleada, onde o núcleo se apresenta com cores variadas, alternando diversos tons de amarelo e vermelho, dependendo da predominância de ferro férrico hidratado $\alpha-\mathrm{FeOOH}$ (goethita) ou ferro férrico anidro $\alpha-\mathrm{Fe}_{2} \mathrm{O}_{3}$ (hematita), principalmente. Muitos contêm mineralizações de quartzo em suas fraturas e cavidades. Nenhuma das amostras apresentou resquícios do sulfeto original em seu interior.

Os ensaios de traço, morfologia e cor foram divididos em quatro grupos básicos, conforme a

\section{TABELA 1.}


TABELA 1 - Comparação da morfologia interna dos agregados

\begin{tabular}{|c|c|c|c|c|c|c|}
\hline Grupo & Núcleo & Borda & Cor do traço & Observações & $\begin{array}{l}\text { Número de } \\
\text { espécimes }\end{array}$ & $\begin{array}{l}\text { Percentua } \\
\%\end{array}$ \\
\hline 01 & $\begin{array}{l}\text { Amarelo, brilho resinoso, } \\
\text { muito poroso }\end{array}$ & $\begin{array}{l}\text { Fina, formando um } \\
\text { invólucro }\end{array}$ & Amarelo & $\begin{array}{l}\text { Mineralizações de } \\
\text { quartzo na forma } \\
\text { de veios e geodos }\end{array}$ & 24 & 40,00 \\
\hline 02 & $\begin{array}{l}\text { Amarelo escuro, mais } \\
\text { denso, mas ainda poroso e } \\
\text { com considerável } \\
\text { absorção de água. }\end{array}$ & $\begin{array}{l}\text { Espessa, evidenciando a } \\
\text { natureza radial do agregado }\end{array}$ & Amarelo & & 20 & 33,30 \\
\hline 03 & $\begin{array}{l}\text { Vermelho carmim, ainda } \\
\text { muito poroso e } \\
\text { susceptível à absorção de } \\
\text { água em níveis ainda } \\
\text { elevados }\end{array}$ & $\begin{array}{l}\text { Espessa, evidenciando a } \\
\text { natureza radial do agregado }\end{array}$ & Vermelho & & 10 & 16.70 \\
\hline 04 & $\begin{array}{l}\text { Cinza aço, pouca } \\
\text { porosidade, aspecto já } \\
\text { metálico, evidenciando } \\
\text { estrutura radial }\end{array}$ & $\begin{array}{l}\text { Aspecto radial, mais } \\
\text { desidratado que os outros } \\
\text { espécimes }\end{array}$ & Vermelho & & 6 & 10,00 \\
\hline
\end{tabular}

Algumas das amostras apresentaram

cavidades em seu interior, as quais estavam preenchidas por quartzo em alguns casos. A cor vermelha já indica um grau maior de desidratação e formação de hematita. A FIGURA 12 ilustra algumas feições internas nas amostras.


FIGURA 12: Secção mostrando estrutura radial concêntrica e núcleo em pirita globular goethitizada- a cor vermelha no núcleo indica maior desidratação. Morro das Balas, Formiga- MG

Esses dados indicam que há diversos estágios de alterações que vão desde estruturas globulares com a parte interna friável, porosa e pulverulenta, com camadas distintas, até exemplares com a parte interna de aspecto metálico e maior densidade, condicionados pelas variações climáticas, tipo de ataque químico por agentes naturais, entre outros fatores. Os espécimes sofreram mais de uma pseudomorfose e mineralização, e, atualmente têm sido destruídos pelo intemperismo físico e químico por estarem expostos na superfície.
Milhares de glóbulos com morfologia variada foram coletados pelo primeiro autor para coleção e estudo, ao longo de mais de trinta e cinco anos. Por meio da análise nas regiões citadas, tornou-se bem claro que o grau de evolução pseudomórfica e morfologia das amostras estão subordinados a condições intrínsecas do local de coleta.

\section{Conclusão}

Os pseudomorfos estão restritos ao domínio sedimentar do Grupo Bambuí, hábito predominante cúbico e combinações deste, apresentando diferentes 
graus de pseudomorfose e intemperismo, com dimensões médias entre 1 e $2 \mathrm{~cm}$ e hábitos subordinados às condições físico-químicas locais. O hábito octaédrico é menos frequente e cristalizações são de gerações diferentes. As formas globulares são mais abundantes que os cristais isolados.

\section{Referências}

1. COMIG, Companhia Mineradora do Estado de Minas Gerais. Mapa Geológico do estado de Minas Gerais. Edição especial, 2003, BRASIL.

2. CODEMIG, Companhia Mineradora do Estado de Minas Gerais. Programa mapeamento geológico do estado de Minas Gerais. Projeto fronteiras de Minas Gerais. Contrato CODEMIG 3473, FUNDEP 19967. 2015. Brasil.

\section{FOLHA FORMIGA Mapa Geológico} do estado de Minas Gerais. Edição especial, 2013, BRASIL.

4. FONSECA, Anísio Cláudio. Rios.

Geologia geral do município de Formiga-MG. 2015. 170p. Disponível em<

http://www.formiga.mg.gov.br/arquivos /turismo/geologia >. Acesso em: março de 2019.

5. General pyrite information. Disponível em <http://www.webmineral.com/data/Pyrite.shtml\# .XI2DSMlKjcc>. Acesso em: março 2019.

6. LEINZ Victor \&; AMARAL, Sérgio E. Geologia geral. 11. ed. São Paulo: Nacional, 1989. $397 \mathrm{p}$.

7. BRANCO, P.M. Dicionário de mineralogia. 2. ed. Porto Alegre: UFRGS, 1982. p. 264.

8. DEER, W.A. Minerais constituintes das rochas. $1^{\mathrm{a}}$. ed. Lisboa Fundação Calouste Gulbenkian, 1981. p. 558.

9. BERNER, R. Sedimentary pyrite formation: An update. Department of Geology and Geophysics, Yale University, New Haven, Connecticut 065 II. 1983)
10. SCHIEBER, Jurgen. GORDON, Bayrd. On the Origin and Significance of Pyrite Spheres in Devonian Black Shales of North America. Journal of Sedimentary Research, 71(1):155-166, 2001.

11. SIMKISS, K. \& WILBUR, K.M. (1989). Biomineralization - Cell Biology and Mineral Deposition. Academic Press, New York, p. 337.

12. WILKIN, R.T. \& BARNES, H.L. (1997). Formation processes of framboidal pyrite. Geochimica Cosmochimica Acta, 61: 323-339

13. PIRES, L.C. LACERDA, L.D. Piritas framboidais associadas ao biofilme em sedimentos de manguezal de Coroa Grande, Baía de Sepetiba, RJ. Geochimica Brasiliensis, 22(3) 201-212, 2008.

14. OLIVEIRA, M.G.N. Colonização Inicial da Comunidade Epibentônica em substratos Artificiais na Ilha de Cabo Frio, Arraial do Cabo, RJ. Dissertação. Universidade Estadual do Rio de Janeiro. Rio de Janeiro. 1998. 98 p.

15. Foro de Mineralogia Formativa. Disponível em <http:// www.foro_minerales.com $>$. Acesso em: março 2019.

16. DANA, J.D. Manual de mineralogia. Rio de Janeiro: Livros técnicos e científicos, 1978. p. 42 .

17. MARTINS, T. J. Quilombo do Campo Grande- História que se devolve ao povo. Santa Clara Editora de Livros ltda. ContagemMG. 2008. p. 1032.

18. CUNHA, Euclides da. Os Sertões. São Paulo: Editora Brasiliense S.A., 1985

19. FONSECA, Anísio Cláudio. Rios. Morfologia de rochas lateríticas de Morro das Balas, município de Formiga-MG. 2005. p. 30. (Monografia- Curso de especialização em solos e meio-ambiente). Universidade Federal de Lavras, Lavras, Minas Gerais. 